\title{
The prevalence of multiple sclerosis in Belo Horizonte, Brazil
}

\author{
Prevalência da esclerose múltipla em Belo Horizonte, Brasil \\ Marco A. Lana-Peixoto, Elizabeth R. C. Frota, Gilberto B. Campos, Leonardo P. Monteiro on behalf of the \\ Brazilian Committee for Treatment and Research in Multiple Sclerosis.
}

\begin{abstract}
Investigations on the prevalence rates of multiple sclerosis (MS) around the world have yielded important clues on the interplay between genetic susceptibility and environmental factors. As Brazil is a huge country laid on many latitudes and inhabited by population with distinct ethnic backgrounds, it might be assumed that the frequency of MS varies in its different regions. Objective: To determine the prevalence rate of MS in Belo Horizonte, the capital of the State of Minas Gerais, Southeastern Brazil. Methods: We used six sources to draw up a provisional list of identified cases of MS. Only patients with diagnosis of clinically definite MS according to Poser Committee criteria were included. Results: The calculated crude MS prevalence was 18.1/100,000 inhabitants. Conclusions: The MS prevalence in Belo Horizonte is similar to that found in São Paulo and Botucatu, two other cities in southeastern Brazil with similar ethnic background.
\end{abstract}

Key words: multiple sclerosis, prevalence, Belo Horizonte, Southeastern Brazil.

\section{RESUMO}

Estudos sobre as taxas de prevalência da esclerose múltipla (EM) no mundo têm fornecido importantes evidências do papel da inter-relação dos fatores genéticos e ambientais determinando estas frequências. Como o Brasil é um país muito extenso e com populações de diversas origens étnicas, supõe-se que a frequência da EM seja variável em suas diferentes regiões. Objetivo: Determinar a taxa de prevalência da esclerose múltipla (EM) em Belo Horizonte, capital do estado de Minas Gerais, no sudeste do Brasil. Métodos: Nós usamos seis fontes para a identificação dos pacientes que preenchiam os critérios diagnósticos de EM clinicamente definida de acordo com o Comitê de Poser. Resultados: A taxa de prevalência encontrada foi de 18,1/100.000 habitantes. Conclusões: A prevalência em Belo Horizonte de EM é semelhante à encontrada nos estudos em São Paulo e Botucatu, duas outras cidades na região sudeste do Brasil habitadas por populações com similar origem étnica.

Palavras-Chave: esclerose múltipla, prevalência, Belo Horizonte, região sudeste do Brasil.

Multiple sclerosis (MS) is a demyelinating inflammatory and degenerative disease of the central nervous system (CNS) whose etiology is still unknown. Epidemiological studies have suggested that the interaction between genetic susceptibility and a variety of environmental factors may play a key role accounting for the differences in its prevalence in distinct populations ${ }^{1}$.

In the last few decades, a large number of studies have demonstrated the frequency of MS in all continents². Unfortunately, however, many of these epidemiological studies lack consistent methodological features, such as strict diagnostic criteria, well defined study populations or geographical areas, and complete case ascertainment ${ }^{3}$. Such faults have rendered their results unreliable for comparisons with established data from other geographical areas ${ }^{2,3}$. In Latin America, surveys on the epidemiology of MS are still scanty and most of them exhibit these methodological limitations ${ }^{4-8}$.

Interest in the study of MS in Brazil has markedly increased in the last few years. Yet, most investigations have focused on clinical description of hospital-based or MS Centers cohorts in different parts of the country ${ }^{9-16}$. Other studies have concentrated on the association with HLA ${ }^{17,18}$, the influence of ethnic factors on the phenomenological presentation of the disease $\mathrm{e}^{19}$; the neuropsychological aspects of the disease $\mathrm{e}^{20,21}$ and the impact of the disease on patients' quality of life ${ }^{22}$.

Three papers on the prevalence of MS in well-defined geographical areas in Brazil have been so far published. The first study, in São Paulo city, considered 1990 as the prevalence year and showed a prevalence rate of 4.3 per 100,000 inhabitants ${ }^{23}$. A re-evaluation of this prevalence rate by the same senior author ${ }^{24}$ took 1997 as the prevalence year and, through the use of 
a more complete case ascertainment, yielded a prevalence rate of 15.0 per 100,000 . A third prevalence investigation, conducted in Botucatu, a city located $150 \mathrm{~km}$ from São Paulo, disclosed a prevalence rate of 17 per 100,000 inhabitants ${ }^{25}$.

Herein, we report the MS prevalence rate in Belo Horizonte, in the State of Minas Gerais, also located in Southeastern Brazil. As Belo Horizonte, São Paulo city and Botucatu are all situated in southeastern Brazil, with populations sharing similar ethnic background, it is expected that they all have similar prevalence rates. The data may be helpful for future comparison with other prevalence rates in different geographical regions of the country which are under distinct environment factors and inhabited by populations with different ethnic background.

As Brazil is a huge country laid on many latitudes and inhabited by population with distinct ethnic backgrounds preferentially concentrated in distinct geographic areas, it might be assumed that the frequency of MS varies in different regions of the country. Studies using reliable epidemiological methodology in areas with biological rather than administrative divisions may be helpful to understand the relative relevance of both race and geography as determinant factors of MS frequency in the country.

\section{METHODS}

\section{Area of survey}

The prevalence survey was carried out in the city of Belo Horizonte, the capital of the mountainous state of Minas Gerais in southeastern Brazil and the second most populated state in the country (Fig 1). The city is situated at $19^{\circ}$ South of Equator and covers an area of 331 square kilometers at a mean altitude of 900 meters above sea level. The climate is very pleasant all year long, as the mean annual temperature is $20.5^{\circ} \mathrm{C}$, with little variation during the year, and a mean annual rainfall of $1450 \mathrm{~mm}^{26}$. According to the census, conducted by the Brazilian Institute of Geography and Statistics, the estimated population at the prevalence day (July $1^{\text {st }}, 2001$ ) was 2,238,526, with 1,181,263 women and 1,057,263 men, comprising $52.7 \%$ of Brazilian whites, $39.8 \%$ of mulattoes, $7.3 \%$ of blacks and $0.2 \%$ of Asians. The city was founded about 100 years ago to harbor the government of the state of Minas Gerais. Immigrants from the neighborhood comprised Caucasians, mainly descendants of Portuguese, Spaniards and Italians, and a smaller number of mulattoes and blacks had been settled in the city then. A wave of immigrants from the Middle East, mainly from Syria and Lebanon, arrived in the thirties and forties. Since then, the population in the city could be considered ethnically stable. The major economic activities are manufacturing, trades and services.

Sanitation conditions are good and the health care system is made up of a network of public primary care outpatient clinics which refer patients to three major medical centers, two of them affiliated to the two medical schools within the city area. The private medical care system, on the other hand, comprises 26 general hospitals and a number of specialized clinics. The level of medical organization is high. Most patients with neurological conditions are referred to one of the 150 neurologists and neurosurgeons practicing in the city.

\section{Case ascertainment}

Following approval by the local Ethical Committee, we used the following sources to draw up a provisional nominal list of identified cases of MS: (1) medical records from CIEM MS Research Center, a MS Center at the Federal University of Minas Gerais; (2) files of most neurologists in town, both in their private and hospital-based practice; (3) the case notes of the Department of Neurology of the Federal University of Minas Gerais; (4) files of the major general hospitals within the city area; (5) files of all magnetic resonance imaging services within the survey area; (6) files of the state and the national MS societies; (7) files of the City Health Department which supplies free medication to registered MS patients.

Patients' names were included on the provisional list if they had been labeled as having MS by any of the sources of ascertainment and if they were alive and resident within the city area at the prevalence day. The 2001 Belo Horizonte street index in the telephone directory was used to verify an address as being within the survey area. All nominated patients who had not been examined by any of the authors were

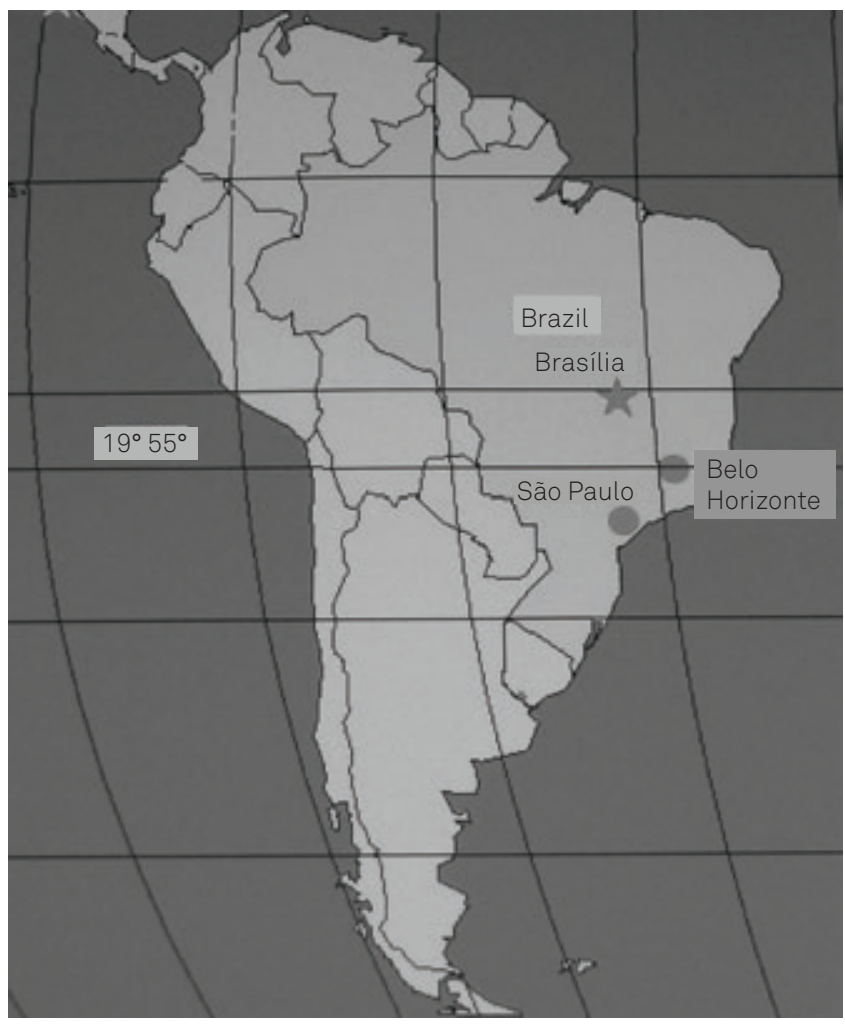

Fig 1. Geographical location of Belo Horizonte in Southeastern Brazil. 
interviewed by phone to provide information regarding the clinical and MRI characteristics of their condition.

Only patients with the diagnosis of clinically definite MS according to Poser Committee criteria were included ${ }^{27}$. The purpose of excluding "probable" MS cases was to attain a higher accuracy of diagnosis aiming at increasing the study strength. The clinical forms of the disease were defined according to consensus criteria established by Lublin et al. ${ }^{28}$. Patients' disability was classified according to Kurtzke Expanded Disability Status Scale (EDSS) ${ }^{29}$ in groups of scores as follows: EDSS 0; EDSS 1.0-3.5; EDSS 4.0-5.5; EDSS 6.0; EDSS 6.5; EDSS 7.0-7.5; EDSS 8.0-9.5.

Details of clinical notes from neurologists and hospital charts were transferred to a pre-coded form which was specially designed to facilitate entry information into a computerized database. For each patient, the following information was recorded: name, sex, date of birth, race, address, city address at the presenting symptom, occupation, date of the presenting symptom, presenting symptom, date of MS diagnosis, MS clinical form and EDSS score at last visit. Information was collected on pre-coded forms created ad hoc and revised. Data were checked for consistency by the senior author and any doubts were cleared up through telephone calls to patients or their assistant neurologists, and the errors were corrected.

\section{RESULTS}

The provisional list contained 453 names labeled as having MS. Based on the interview and neurologic examination, we discarded 44 patients (14 were not resident in Belo
Horizonte at the onset of disease; 20 had the diagnosis of probable MS; and in 10 subjects the medical records and interview did not yield reliable information for the diagnosis of MS). The remaining 409 patients comprised 314 women and 95 men (F:M ratio 3.3). There were 315 Brazilian whites, 82 mulattoes and 12 blacks. The calculated crude MS prevalence rate was 18.1 per 100,000 inhabitants. Table 1 displays the age-specific prevalence rates. The prevalence curve rose to clear-cut peak in the fifth decade of life for both sexes. The mean age at the time of the survey was 35.4 years. Prevalence rates were 3.5 folder higher in women than in men. They were also three and four times more frequent in whites than in mulattoes and blacks (Table 2).

Age at onset of the disease ranged from 4 to 63 years (mean 30.1) and was between 20 and 39 years in about two thirds of patients. Figure 2 shows distribution of patients according to age at disease onset and at the last visit before the prevalence day.

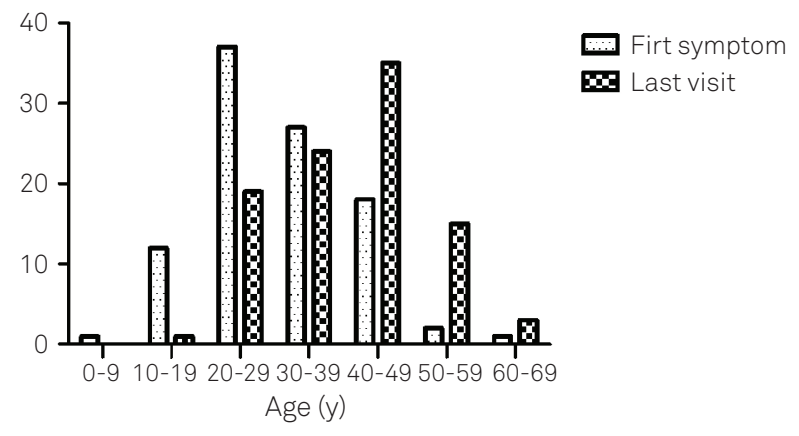

Fig 2. Age distribution at disease onset and at the last visit in the multiple sclerosis population in Belo Horizonte.

Table 1. Age-specific prevalence rates of multiple sclerosis in Belo Horizonte.

\begin{tabular}{lccc} 
Age group & Population at risk & Number of cases & Prevalence rate (per 100,000) \\
$0-9$ & 353,473 & 0 & 0 \\
$10-19$ & 411,970 & 5 & 1.21 \\
$20-29$ & 429,914 & 79 & 18.37 \\
$30-39$ & 363,788 & 101 & 27.76 \\
$40-49$ & 290,449 & 147 & 50.61 \\
$50-59$ & 184,329 & 63 & 34.17 \\
$60-69$ & 116,203 & 13 & 11.18 \\
$70-$ & 88,370 & 1 & 1.13 \\
Total & $2,258,857$ & 409 & 18.27 \\
\hline
\end{tabular}

Table 2. Prevalence rates of multiple sclerosis in Belo Horizonte according to gender and ethnic group.

\begin{tabular}{lccc} 
& Population at risk & Number of cases & Prevalence rate (per 100,000) \\
Women & $1,181,263$ & 314 & 37.6 \\
Men & $1,057,263$ & 95 & 11.1 \\
Whites & $1,179,703$ & 315 & 26.7 \\
Mulattoes & 809,933 & 82 & 9.2 \\
Blacks & 188,221 & 12 & 6.4 \\
\hline
\end{tabular}




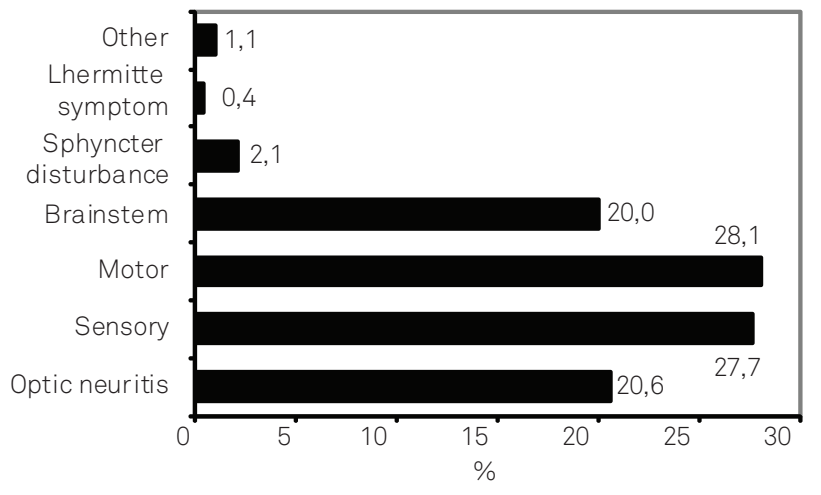

Fig 3. Symptoms at disease presentation in the multiple sclerosis population in Belo Horizonte.

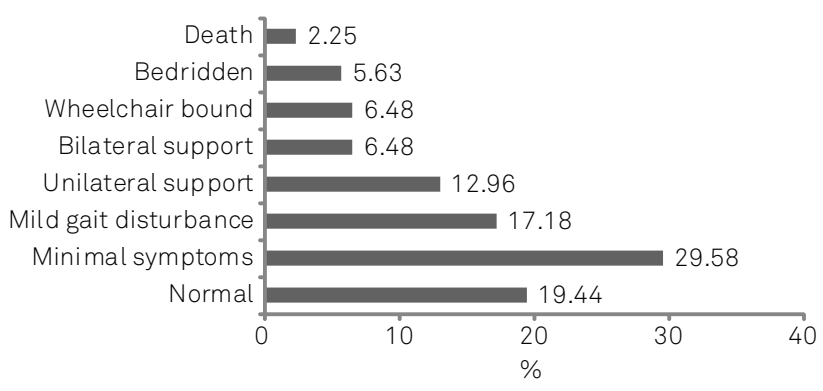

Fig 4. Distribution of the multiple sclerosis population in Belo Horizonte according to some key disability status.

Weakness was the most frequent symptom/sign at presentation, followed by sensory disturbances, optic neuritis and brainstem/cerebellar disturbances (Fig 3). At the time of the survey, the clinical course of the disease was as follows: 261 patients had relapsing-remitting MS, 48 primary progressive MS, 78 secondary progressive MS, and 22 progressive MS with relapses.

At the last visit, 82 patients had no neurological deficit, 120 had minimal symptoms/signs, 72 mild gait disturbances, 54 required unilateral support, 27 bilateral support, 27 were bound to wheelchair and 27 were bedridden. Fig 4 shows the distribution of the population according to some key scores of the EDSS.

\section{DISCUSSION}

The present study shows that the prevalence rate of MS in Belo Horizonte is 18 per 100,000 inhabitants, a figure close to that found in São Paulo city and Botucatu. These three cities share ethnic, economical and cultural features, and are situated in Southeastern Brazil. Two sequential prevalence studies in São Paulo city separated by an interval of seven years and conducted by the same senior author have shown strikingly different rates ${ }^{23,24}$. In the first investigation, for the prevalence year of 1990, 486 MS cases (325 women and 161 men) were identified and the prevalence rate was 4.3 per 100,000. In the second survey, for the prevalence year of 1997, the number of identified cases increased to 1483 (1076 men and 407 women) and the rate changed to 15.0 per 100,000. Probably, a more complete case ascertainment and the more widely use of the magnetic resonance imaging as an ancillary diagnostic tool can be accounted for the over three fold increase in the number of recognized patients. It has been pointed out that an almost universal rule concerning prevalence of MS is that later studies of the same area show higher rates than do earlier surveys and that modern laboratory diagnostic investigations may potentially influence prevalence rates ${ }^{2}$. The different results of these sequential surveys in São Paulo city illustrate that the extent investigators must care about accuracy of diagnosis and completeness of case ascertainment.

Notwithstanding conducted under a more restrictive inclusion criteria, as patients were included only if they both fulfilled Poser's criteria for the diagnosis of clinically definite $\mathrm{MS}^{27}$ and if were living in Belo Horizonte at the time of the first symptom of the disease, the present survey yielded a higher prevalence rate in Belo Horizonte than that found in São Paulo studies. Therefore, the strict methodology strengthens the reliability of the present prevalence study.

Yet, the prevalence rate as provided by the present survey is probably underestimated as we failed to have access to data from some small hospitals and rehabilitation clinics, as well as to files from about one-fourth of all neurologists in town. On the other hand, if one takes into account that the in the present study we surveyed all major hospitals and all MRI services in the city, as well as the file of the State Health Agency, which provides free medication for all relapsing-remitting MS patients in the state, and additionally scrutinized the files of the MS societies in the city, one may be able to evaluate how careful we have been to catch all MS patients living in the city. The resulting data provide, for the first time in Latin America, the onset-adjusted prevalence rate, which is a more precise measure than crude prevalence ${ }^{3}$.

Comparison of MS prevalence rates in Belo Horizonte and São Paulo may further illustrate the increasing difficulty of case ascertainment in very large and highly populated areas. This is still more difficult if a well-organized and centralized registry system is not available, as it happens in both cities. Identification of MS patients living in a 10 million inhabitants city, like São Paulo, with a huge number of general hospitals, outpatient clinics and hundreds of practicing neurologists may be a herculean task. In fact, as surveying Belo Horizonte, a city four times smaller than São Paulo, we have experienced enormous difficulties contacting neurologists, checking diagnosis and exploring the necessary clinical information. For a number of cases, we had to interview patients by telephone or even examine them for differential diagnosis.

On the other hand, only a few smaller sized communities in Brazil may fit appropriate for MS prevalence studies as most of them lack well organized medical care systems and 
are usually bereft of resources to identify their MS patients with acceptable diagnostic accuracy.

Seemingly better fitted to epidemiological surveys, the university city of Botucatu, situated $150 \mathrm{~km}$ from São Paulo city, has 103,000 inhabitants who are provided with high-level medical care in a well-organized health system. The recently reported prevalence rate of 17 per 100,000 in Botucatu ${ }^{25}$ is very close to ours. However, it is well known that very small gains or losses in the number of cases may cause enormous change in the prevalence rate in places where its frequency is not high. In spite of Botucatu's highly organized health system, the small number of recognized cases in its MS prevalence study makes this caution necessary.

These recent formal epidemiological studies of MS performed in Southeastern Brazil have established a prevalence rate much higher in the country than that previously estimated through less appropriate survey methodology ${ }^{30}$.

The distribution of MS in Latin America is still largely unknown as few surveys employing formal epidemiological methodology have been conducted. The first data on MS frequency in Latin America was based on a study of MS among government employees and their dependents in Mexico City ${ }^{31}$. The calculated prevalence rate was 1.6 per 100,000 inhabitants. More recently, a few papers emphasized an increased frequency of identified cases of MS in different areas of the country. A survey in the state of Chihuahua, at the border with the United States, collected 98 MS patients corresponding to a prevalence rate of 12 per 100,0006 In Colombia, whose territory is divided by the tropic of Capricorn, prevalence rates from 1.48 to 4.98 per 100,000 were found in the five provinces of the country ${ }^{5}$ whereas in Bogotá a prevalence of 4.4 was recently reported ${ }^{32}$. Interesting enough, the survey in the different Colombian provinces ${ }^{5}$ shows a relatively lower prevalence in Antioquia, whose population is mainly made up of Caucasians directly descendants from Spaniards, differently from the predominantly miscegenated residents of other provinces ${ }^{5}$. In Argentina, data collected from four hospitals in Buenos Aires suggested prevalence rates between 15.6 to 17.5 per $100,000^{4}$ whereas in Uruguay the rate of 17.6 per 100,000 has been reported ${ }^{7}$.

The present study shows that MS prevalence rate in Belo Horizonte is similar to that found in São Paulo ${ }^{24}$ and Botucatu $^{25}$, two other cities in Southeastern Brazil, as well as to rates reported in Buenos Aires ${ }^{4}$ and Uruguay ${ }^{7}$, but much higher than those from Colombian ${ }^{5,32,33}$ and Mexican studies $^{6,31}$.

As Brazil's territory covers tropical and subtropical latitudes, it is probable that the frequency of MS is direct related to the increase of south latitude. Such a gradient has been reported in other countries, as in Australia ${ }^{34}$. However, one has to keep in mind that a stronger Caucasian genetic background distinguishes the population of Southeastern from those living in Northern and Northeastern Brazil. Good quality surveys of MS prevalence, associated with genetic characterization of populations in selected Brazilian cities, may shed some light upon the interaction of genetic and environment factors determining the frequency of MS in different populations and regions of the country.

\section{References}

1. Compston A, Wekerle $H$. The genetics of multiple sclerosis. In: Compston A, Canfavreux C, McDonald I, et al. (Eds). McAlpine's Multiple Sclerosis. 4th edition. Philadelphia: Churchill Livingstone Elsevier; 2006. p. 113-182.

2. Compston A, Confavreux C. The distribution of multiple sclerosis. In: Compston A, Canfavreux C, McDonald I, et al. (Eds). McAlpine's Multiple Sclerosis. 4th edition. Philadelphia: Churchill Livingstone Elsevier; 2006. p. 71-105

3. Poser CM, Brinar VV. The accuracy of prevalence rates of multiple sclerosis: a critical review. Neuroepidemiology 2007;29:150-155.

4. Cristiano E, Patrucco L, Garcea O, et al. Prevalence of multiple sclerosis in Buenos Aires, Argentina, using the capture-recapture method. Eur J Neurol 2009;16:183-187.

5. Sánchez JL, Aguirre C, Arcos-Burgos OM, et al. Prevalencia de la esclerosis múltiple en Colombia. Rev Neurol 2000;31:1101-1103.

6. Velásquez MM, López Prieto, Marquez JC, Riviera CM, Vargas ML. Características epidemiológicas de la esclerosis múltiple en un estado fronteirizo con los Estados Unidos de Norteamérica. Arch Neuroscien Mex 2002;7:147-150.

7. Ketzoian C, Oehninger C, Alcántara J, et al. Estudio de la prevalencia de la esclerosis múltiple en el Uruguay. Acta Neurol Colomb 1999;15 (Suppl):S6.

8. Cristiano E, Patrucco L, Rojas JI. A systematic review of the epidemiology of multiple sclerosis in South America. Eur $\mathrm{J}$ Neurol 2008;15:1273-1278.
9. Arruda WO, Scola RH, Teive HA, Werneck LC. Multiple sclerosis: report on 200 cases from Curitiba, Southern Brazil and comparison with other Brazilian series. Arq Neuropsiquiatr 2001;59:165-170.

10. Ferreira ML, Machado MI, Vilela ML, et al. Epidemiology of 118 cases of multiple sclerosis after 15 years of follow-up on the reference center of Hospital da Restauração, Recife, Pernambuco, Brazil. Arq Neuropsiquiatr 2004,62:1027-1032.

11. Fragoso YD, Fiore AP. Description and characteristics of 81 patients attending the Reference Center for Multiple Sclerosis of the coastal region of the state of São Paulo-Brazil. Arq Neuropsiquiatr 2005;63:741-744.

12. Grzesiuk AK. Clinical and epidemiologic characteristics of 20 patients with multiple sclerosis in Cuiabá-Mato Grosso, Brazil. Arq Neuropsiquiatr 2006;64:635-638.

13. Santos EC, Yokota M, Dias NF. Multiple sclerosis: study of patients with relapsing-remitting form registered at Minas Gerais Secretary of State for Health. Arq Neuropsiquiatr 2007;65:885-888.

14. Finkelsztejn A, Cristovam Rdo A, Moraes GS, et al. Clinical features of multiple sclerosis in the south of Brazil: a partial analysis. Ara Neuropsiquiatr 2009;67:1071-1075.

15. Kaimen-Maciel DR, Medeiros M, Pisori R, Biaggio C, Rocha F, Lopes LHG. The prevalence of multiple sclerosis in two cities in north of Paraná State, Brazil. Mult Scler 2004;10 (Suppl):S158.

16. Gama PD, Trigo LX, Andrade CRR, Sala CR. Epidemiological study of multiple sclerosis in the city of Sorocaba, Brazil. Arq Neuropsiquiatr 2004;62 (Suppl):S13. 
17. Alves-Leon SV, Papais-Alvarenga R, Magalhães M, Alvarenga M, Thuler LC, Fernández y Fernandez O. Ethnicity-dependent association of HLA DRB1-DQA1-DQB1 alleles in Brazilian multiple sclerosis patients. Acta Neurol Scand 2007;115:306-311.

18. Brum DG, Barreira AA, Louzada-Junior P, Mendes-Junior CT, Donadi EA. Association of the HLA-DRB1*15 allele group and the DRB1*1501 and DRB1*1503 alleles with multiple sclerosis in White and Mulatto samples from Brazil. J Neuroimmunol 2007;189:118-124.

19. Ferreira Vasconcelos CC, Santos Thuler LC, Cruz dos Santos GA, et al. Differences in the progression of primary progressive multiple sclerosis in Brazilians of African descent versus white Brazilian patients. Mult Scler 2010;16:597-603.

20. Negreiros MA, Mattos P, Landeira-Fernandez J, Paes RA, Alvarenga RP. A brief neuropsychological screening test battery for cognitive dysfunction in Brazilian multiple sclerosis patients. Brain Inj 2008,22:419-426.

21. Haase VG, Lima Ede P, Lacerda SS, Lana-Peixoto MA. Development of the Brazilian version of the Multiple Sclerosis Functional Composite Measure (MSFC-BCTRIMS): pilot study. Arq Neuropsiquiatr 2004;62:363-369.

22. Fragoso YD, Finkelsztejn A, Giacomo MC, Russo L, Cruz WS. The effect of multiple sclerosis on the professional life of a group of Brazilian patients. Arq Neuropsiquiatr 2010;68:914-917.

23. Callegaro D, Lolio CA, Radvany J, Tilbery CP, Mendonça RA, Melo AC. Prevalence of multiple sclerosis in the city of São Paulo, Brazil, in 1990. Neuroepidemiology 1992;11:11-14.

24. Callegaro D, Goldbaum M, Tilbery CP, et al. The prevalence of multiple sclerosis in the city of São Paulo, Brazil, 1997. Acta Neurol Scand 2001;104:208-213.
25. Rocha FC, Herrera LC, Morales RR and The Brazilian Committee for Treatment and Research in Multiple Sclerosis. Multiple sclerosis in Botucatu, Brazil. A population study. Mult Scler 2002;8(Suppl):S41-S42.

26. Instituto Brasileiro de Geografia e Estatística (IBGE). Available from: www.ibge.gov.br.

27. Poser CM, Paty DW, Scheinberg L, et al. New diagnostic criteria for multiple sclerosis: guidelines for research protocols. Ann Neurol 1983;13:227-231.

28. Lublin FD, Reingold SC. Defining the clinical course of multiple sclerosis: results of an international survey. National Multiple Sclerosis Society (USA) Advisory Committee on Clinical Trials of New Agents in Multiple Sclerosis. Neurology 1996;46:907-911.

29. Kurtzke JF. Rating neurological impairment in multiple sclerosis: an expanded disability status scale (EDSS). Neurology 1983;33:1444-1452.

30. Christensen JC. Multiple sclerosis: some epidemiological clues to its etiology. Acta Neurol Latinoam 1975;21:66-85.

31. Alter M, Olivares L. Multiple sclerosis in Mexico. An epidemiologic study. Arch Neurol 1970;23:451-459.

32. Toro J, Sarmiento Ol, Díaz del Castillo A, et al. Prevalence of multiple sclerosis in Bogotá, Colombia. Neuroepidemiology 2007;28:33-38.

33. Sánchez JL, Palacio LG, Uribe CS, et al. Clinical features of multiple sclerosis in a genetically homogenous tropical population. Mult Scler 2001;4:227-229.

34. Hammond SR, McLeod JG, Millingen KS, et al. The epidemiology of multiple sclerosis in three Australian cities: Perth, Newcastle and Hobart. Brain 1988;111:1-25. 